\title{
Arab Woman's Relationship With Her Spouse and the Severity of Postpartum Depression and Distorted Thinking
}

\author{
Emad Gith ${ }^{1,2} \& 3$ \\ ${ }^{1}$ Sakhnin Academic College for Teacher Education, Sakhnin, Israel \\ ${ }^{2}$ Educational Psychological Services, Arraba Village, Israel \\ ${ }^{3}$ Department of Psychology, Ethics, and Law, International Center for Health, Law, and Ethics, Faculty of Law \\ at the University of Haifa, Haifa, Israel \\ Correspondence: Emad Gith, PhD, Department of Psychology, Ethics, and Law, International Center for Health, \\ Law, and Ethics, Faculty of Law at the University of Haifa, Haifa 3498838, Israel.
}

Received: February 14, 2018

Accepted: March 1, 2018

Online Published: March 2, 2018

doi:10.20849/ajsss.v3i1.322

URL: https://doi.org/10.20849/ajsss.v3i1.322

\begin{abstract}
The objective of this study was to examine the correlation between the Arab woman's relationship with her spouse and the severity of depression. The Edinburgh Postnatal Depression Scale (EPDS) was used to focus on the cognitive and affective features of depression. This study involved long-term research.

This study found a correlation between women's problematic relationships with their spouses and the severity of depression. This study has both clinical and research implications. Clinically, the importance of psychosocial factors and social support for a new mother calls for the consideration of these factors in the design of antenatal and postnatal care plans for women.
\end{abstract}

Keywords: postpartum depression, Arab woman, relationship with spouse, distorted thinking

\section{Background}

\subsection{Postpartum Depression}

PPD is a complex public health and psychological problem that has negative effects on the mother and her infant. There is still relatively limited information and research on PPD in Israel, specifically among Arab women (Abiodun, 2006; Andajani-Sutjahjo et al., 2007; Felice et al., 2004).

\subsection{PPD in Arab Society}

Alfayumi-Zeadna, Kaufman-Shriqui, Zeadna, and Shoham-Vardi (2015) examined PPD among Arab Bedouin women in southern Israel. Their study revealed a high prevalence of PPD. The unique risk factors that predicted PPD were a lack of support from the husband, a history of emotional problems, low income, low level of education, high marital conflicts, and unplanned pregnancy. Similarly, Mohammad, Gamble, and Creedy (2010) investigated the prevalence of depression during pregnancy and the postpartum period among Jordanian women. They reported high rates of antenatal and postnatal depression. Factors such as stress, anxiety, financial problems, perceived lack of parenting knowledge, difficult relationship with the mother-in-law, unplanned pregnancy, and low self-efficacy were associated with antenatal depression. These findings suggest that Arab women need support to prepare for pregnancy and birth.

The individual is surrounded by the family (regardless of the family's living arrangements), which prevents the individual from feeling alone. Loneliness is a significant contributor to depression among many in Western society and occasionally even leads to suicide attempts. On the other hand, a person who is embraced by the family may have a limited ability to express emotions; therefore, the person's inner struggles are expressed through body language and physical symptoms.

\subsection{Marital Relationship and PPD Among Women}

In modern society, there is a correlation between PPD and the woman's relationship with her spouse. If the woman is depressed, the woman typically feels overwhelmed and may feel that her partner is not very helpful. 
The woman has no support from the community and social roles; therefore, the marital relationship between the woman and her spouse is negatively affected (Cunningham \& Thornton, 2006).

In the other hand, among traditional women, no significant correlation exists between PPD and the woman's relationship with her spouse in the literature. Saleh, El-Bahei, El-Hadidy \& Zayed (2013) indicated that Egyptian traditional women receive helping with housekeeping and care for the new baby from family and husbands. Therefore, social support from their husband helps them to ensure motherhood status, a factor that helps them which prevent PDD.

\subsection{Research Question}

Is there a correlation between PPD and the woman's relationship with her spouse?

\section{Hypothesis}

A correlation exists between the woman's relationship with her husband and the degree of depression. Among traditional women, no significant correlation exists between PPD and the woman's relationship with her spouse. This is not true for modern women, who suffer from depression when their relationships with their spouses are not intact.

\section{Method}

\subsection{Tools}

\subsubsection{Questionnaire}

The questionnaire was developed specifically for this study based on a broad theoretical background that contained 45 questions. A statistical analysis of the answers yielded the Indics: the woman's relationship with her spouse's family (5 items), sample item: I receive a social support from my husband. The woman's approach to her spouse's control over her life (5 items), sample item: my husband makes decisions alone. The woman's approach to her relationship with her mother (6 items), sample item: my mother should help me in baby growing.

The rating method was from 1 (Disagree Strongly), 2(Disagree), 3(Slightly Disagree), 4 (Slightly Agree), 5(Agree), 6 (Agree Strongly).

A general demographic questionnaire was developed. The demographic variables included age, gender, marital status, education level, and depression experience. Demographic questions are designed to elicit information from respondents concerning their personal characteristics and social background.

Items with a poor fit were removed using two closely related criteria. To compute the criteria, the score range was divided into four score levels in such a way that each of the score groups had an approximately equal number of respondents. Many of the remaining items had significant values.

Relationship with husband included: the woman's approach to her spouse's control over her life (5 items), sample item: my husband makes decisions alone and the woman's attitude toward the distribution of roles between herself and her spouse.

\subsection{Validity}

The researcher has given a questionnaire on a similar construct, to see if the results were related. It is used in assessing construct validity.

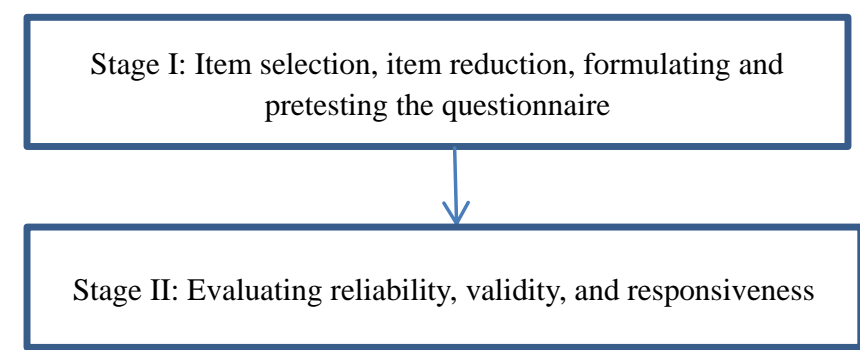

Figure 1. Questionnaire development

\subsection{Edinburgh Postnatal Depression Scale}

The Edinburgh Postnatal Depression Scale (EPDS) is a unique assessment tool developed by Cox et al. (1987) to diagnose PPD. This scale has been used on Arab women in Israel (Glaser et al., 2011, 2012). The questionnaire 
is simple and easy to use and has been proven to be a good predictor of PPD. It has been shown to yield high specificity and sensitivity rates. This questionnaire has been used by Arab societies and in the Persian Gulf principalities (Abou-Saleh \& Gubash, 1997), with a high validity rate.

The questionnaire contains a 10-item scale, which focuses on the cognitive and affective features of depression. It is a self-report scale that has been validated for use during pregnancy and the postnatal period. A score of above 12 is widely used to indicate probable depressive disorder among women, although it cannot confirm a diagnosis of depression.

Responses to the test are scored as $0,1,2$, or 3 according to the increased severity of the symptom. The total score of the EPDS is determined by calculating the scores for each of the 10 items. The cut-off scores range from 9 to 13 points. Therefore, a woman scoring 9 or more points or indicating any depression - that is she scores 1 or higher on question 10 - indicating depression.

The internal consistency of the current EPDS version using Cronbach's alpha coefficient was found 0.804. Ghubash, Abou-Saleh, and Daradkeh (1997) validated the Arabic version of the EPDS. They reported a sensitivity of $91 \%$ (specificity of $84 \%$ ) at a cut-off score of 10 and a sensitivity of $73 \%$ (specificity of $90 \%$ ) at a cut-off score of 13 .

\section{Research Process}

The analysis was conducted to examine the following:

Within-subject (dependent) variables: depression levels before and after delivery

\subsection{Participants}

The study included 206 women, four of whom did not complete the study (two because of miscarriages and two for unknown reasons). The average age of the women was 22.20 ( $\mathrm{SD}=2.58)$. Among the participants, $1.5 \%$ completed elementary school, $7 \%$ completed middle school, $18 \%$ completed high school, $37 \%$ studied in college, and $36.5 \%$ studied in universities. In terms of profession, $49 \%$ were students, $30 \%$ were housewives, $6 \%$ were clerks, $14 \%$ were teachers, and $1 \%$ was social workers.

\section{Results}

\subsection{Correlation Between the Relationship With the Spouse and the Degree of Depression}

An analysis of the Pearson correlation between the difficulty of the woman's relationship with her spouse and the severity of depression revealed a significant positive correlation $(r=.27, p<.01)$.

We found that correlations of this kind are much stronger among modernized women $(r=.25, p<.01)$ who affected by distorted thinking. In some cases, a reverse correlation was found for traditional women-the less confident the woman felt in her relationship with her husband, the less likely she was to suffer from depression $(r=-.11, n . s)$.

The only index that yielded different results was the woman's approach to the distribution of roles between men and women. There was a stronger correlation between dissatisfaction with relationships and depression among traditional women. Nevertheless, this should be interpreted cautiously, as it pertains only to the eight women in the study group who were classified as traditional under this parameter who were in depression.

Table 1. Correlation between difficult relationships with spouses and the degree of depression

\begin{tabular}{lll}
\hline Measure & \multicolumn{2}{l}{ Pearson correlation } \\
\hline & Traditional & Modern \\
& $N=100$ & $N=102$ \\
\hline Relationship with spouse's family & 8 - in depression & 32 in depression \\
Approach to social criticism & .04 & $-.29^{* *}$ \\
Approach to spouse's control over the woman's life & -.11 & $-.15^{*}$ \\
Attitude toward distribution of roles between men and women & .09 & $.53^{* *}$ \\
Self-expression and realization & $.64^{* *}$ & .29 \\
Attitude toward the increased rights that society grants to men & -.24 & $.25^{* *}$ \\
Approach toward sexual relations before marriage & .06 & $.27^{* *}$ \\
Approach to the woman's relationship with her mother & -.03 & $.45^{* *}$ \\
\hline
\end{tabular}
Note: $* * p<.01$. 
An analysis of the Pearson correlation was performed between difficult relationships with spouses and the degree of depression among traditional women and among modern women who identified as crossing the clinical threshold for depression. The number of all traditional women was 100 ( 8 of them were identified as crossing the clinical threshold for depression) and 102 traditional (32. of them were identified as crossing the clinical threshold for depression).

\subsection{Multiple Regression Analysis: Predicting PPD}

Multiple regression analysis was conducted to evaluate how well the measures predicted PPD among both traditional and modern Arab women. The predictors were the indices: depression level before delivery, and the woman's relationship with her husband. The linear combination of strength measures was significantly related to PPD, $\mathrm{F}(3,179)=5.1, \mathrm{p}<.01$. The sample multiple correlation coefficient was .43 , indicating that approximately $18 \%$ of the variance of PPD in the sample can be accounted for by the linear combination of strength measures.

With regard to the strength of the individual predictors, all the bivariate correlations between the measures and PPD were significant $(\mathrm{p}<.05)$. The most contribution was depression level before delivery (negative Beta coefficient of Time 1 depression predicting Time 2 depression can be interpreted as negative correlation, so that if Time 1 depression increase, Time 2 depression decrease) and second to relationship with husband (see Table 2).

Table 2. Hierarchical multiple regression analysis predicting postpartum depression

\begin{tabular}{lllll}
\hline Predictors & $\boldsymbol{B}[\mathbf{9 5 \%} \mathbf{C I}]$ & $\boldsymbol{\beta}$ & $\begin{array}{l}\text { Squared } \\
\text { correlation }\left(\boldsymbol{s} \boldsymbol{r}^{2}\right)\end{array}$ & $\begin{array}{c}\text { part } \\
\text { p-value }\end{array}$ \\
\hline Depression & $-0.210[-0.345,-0.076]$ & -0.256 & .062 & $.002^{* *}$ \\
Relationship with husband & $-0.446[-1.093,0.201]$ & -0.113 & .012 & .01 \\
$R^{2}=.43^{* *}$ & & & & \\
\hline ote: ${ }^{*} p<.05 ;{ }^{* *} p<.01 ;{ }^{* * *} p<.001$. & & &
\end{tabular}

\section{Discussion}

The objective of this study examined the correlation between the woman's relationship with her spouse and the severity of depression and distorted thinking.

This study hypothesized that no correlation exists between PPD and the woman's relationship with her husband among traditional women. This study found a correlation between women's problematic relationships with their spouses and the severity of depression and distorted thinking. Previous studies predicted a high prevalence of PPD when the woman lacks support from her husband and has a history of emotional problems with him (Alfayumi-Zeadna et al., 2015). Other studies identified spousal and parental relationships as risk factors for PPD (Kumar \& Robson, 1984; O’Hara, Neunaber, \& Zekoski, 1984).

While this finding reflects a tendency of the entire research population, an analysis of the correlation between problematic relationships and the women's degree of traditionalism showed that the more traditional the woman is, the less she struggles with problematic relationships. This supports the hypothesis that traditional women tend to accept their relationships with their spouses as they are (Kumar \& Robson, 1984).

This study has both clinical and research implications. Clinically, the importance of psychosocial factors and social support for a new mother calls for the consideration of these factors in the design of antenatal and postnatal care plans for women.

This study was not without limitations. It may be difficult to generalize the findings to the total population of Arab women due to the differences within the Arab society itself.

\section{References}

Al-Krenawi, A., \& Graham J. R. (2004). Somatization among Bedouin-Arab Women: Differentiated by Marital Status. Journal of Divorce \& Remarriage, 42(2), 131-43.

Al-Krenawi, A., \& Lev-Wiesel, R. (1999). Attitude towards marriage and marital quality: A comparison among Israeli Arabs differentiated by religion. Family Relations, 48, 51-56. 
American Psychiatric Association. (2013). Diagnostic and statistical manual of mental disorders (5 ${ }^{\text {th }}$ ed.). Arlington, VA: American Psychiatric Association.

Andajani-Sutjahjo, S., Manderson, L., \& Astbury, J. (2007). Complex emotions, complex problems: understanding the experiences of perinatal depression among new mothers in urban Indonesia. Cult. Med. Psychiatry, 31, 101-122.

Beck, C. T. (1996a). The lived experiment of postpartum depression: A phenomenological study. Nursing Research, 41(3), 166-170.

Beck, C. T. (1996b). Postpartum depressed mothers' experiences interacting with their children. Nursing Research, 45(2), 98-104.

Brockington, I. F., Cernik, K. F., Schofield, E. M., Downing, A. R., Francis, A. F., \& Keelan, C. (1981). Puerperal Psychosis. Phenomena and diagnosis. Arch. Gen. Psychiatry, 38, 829-833.

Chandran, M., Tharyan, P., Muliyil, J., \& Abraham, S. (2002). Post-partum depression in a cohort of women from a rural area of Tamil Nadu, India: Incidence and risk factors. British Journal of Psychiatry, 181, 499-504.

Clarke, P. S. (2004). Causal analysis of individual change using the difference score. Epidemiology, 15(4), 414-421.

Cunningham, M., \& Thornton, A. (2006). The influence of parent's marital quality on adult children's attitudes toward marriage and its alternatives: Main and moderating effects. Demography, 43, 659-672.

Ghubash, R., Abou-Saleh, M. T., \& Daradkeh, T. K. (1997). The validity of the Arabic Edinburgh Postnatal Depression Scale. Social Psychiatry and Psychiatric Epidemiology, 32, 474-476.

Glasser, S., Tanous, M., Shihab, S., Goldman, N., Ziv, A., \& Kaplan, G. (2012). Perinatal depressive symptoms among Arab women in northern Israel. Maternal and Child Health Journal, 16, 1197-1205.

Saleh, el-S., El-Bahei, W., Del El-Hadidy, M. A., \& Zayed, A. (2013). Predictors of postpartum depression in a sample of Egyptian women. Journal of Neurosychiatric Disease and Treatment, 9, 15-24.

\section{Copyrights}

Copyright for this article is retained by the author(s), with first publication rights granted to the journal.

This is an open-access article distributed under the terms and conditions of the Creative Commons Attribution license (http://creativecommons.org/licenses/by/4.0/). 